\title{
Maltrato infantil: la neurobiología, estrategia de estudio para el siglo XXI
}

\section{Child abuse: neurobiology, a study strategy for the $21^{\text {st }}$ century}

Arturo Loredo-Abdalá, Abigail Casas-Muñoz, Verónica Cerezo-Cantú, Oscar Gabriel Carballido-Moreno, Norma Aylin Ordoñez-Franco

\begin{abstract}
Resumen
El maltrato infantil es un grave problema de salud pública con alcance mundial. Aunque las estrategias para atenderlo y prevenirlo han aumentado, éstas han sido insuficientes. Es innegable que situaciones sociales (pobreza, el analfabetismo, los usos y costumbres) u otros determinantes para la salud enmascaran la frecuencia y las consecuencias de esta situación médico-social-legal de la humanidad. El conocimiento de la neurobiología implicada en el maltrato infantil ofrece nuevos campos de investigación, en un intento para resolver cuatro situaciones neuroinmunogenéticas y el desarrollo de estrategias de prevención terciaria del problema: 1) ¿Es posible precisar la génesis de la "replicación transgeneracional" del maltrato infantil? 2) ¿Pueden conocerse los genes que intervienen en este fenómeno? 3) ¿La epigenómica puede ser un área de estudio para conocer el mecanismo de cómo prevenir el maltrato infantil? y 4) ¿Existe un medicamento, alimento o sustancia natural que modifique la respuesta de un gen mediante diversos elementos "dañinos" del medio ambiente?. Para entender estos problemas es indispensable conocer los conceptos básicos de agresividad y violencia del hombre ante el estrés; la neuroanatomía, neurofisiología y consideraciones neurobioquímicas en estas situaciones, destacando la intervención del sistema límbico (amígdala, hipocampo) del cuerpo calloso y de la corteza prefrontal, así como la función de los genes conocidos que participan en el desarrollo de la misma. Es importante precisar si un medicamento, un alimento o una sustancia natural puede modificar las acciones de los genes implicados.
\end{abstract}

PALABRAS CLAVE: Maltrato infantil; neurobiología; epigenética; replicación transgeneracional.

\section{Abstract}

Child abuse is a serious public health problem worldwide. Although the strategies to assist and prevent it have increased, these have been insufficient. It is undeniable that social situations such as poverty, illiteracy, customs, as well as other determinants for health, mask the frequency and consequences of the victims of this medical-social-legal pathology of humanity. The knowledge of the Neurobiology involved in MI offers new fields of research to solve four neuroimmunogenetic situations and the development of tertiary prevention strategies for the problem: 1) Is it possible to specify the development of the "transgenerational replication" of the MI? 2) Can the genes involved in the genesis of the "transgenerational replication" of MI be known? 3) Can the implementation of "Epigenomics" be a possible mechanism for the study and preventive treatment of MI? 4) Is there a medicine, a food or a natural substance that can modify the response of a gene to the existence of various elements of the environment?. To understand this problems, it is essential to know the basic concepts of aggressiveness and violence of man; the neuroanatomy, neurophysiology and neurobiochemical considerations in situations of violence. The intervention of the limbic system (amygdala, hippocampus), corpus callosum and prefrontal cortex. The role of known genes that participate in the development of violence. Finally, find a medicine, a food or a natural substance that allows to modify the actions of the genes involved.

KEYWORDS: Child Abuse; Neurobiology; Epigenetics; Trangenerational Replication; Medication; Food; Natural Substances.
Coordinación de Estudios Avanzados sobre el Maltrato Infantil, Instituto Nacional de Pediatría, Ciudad de México.

Recibido: 16 de agosto 2019

Aceptado: 5 de marzo 2020

Correspondencia

Arturo Loredo Abdalá

cainm_inp@hotmail.com

Este artículo debe citarse como

Loredo-Abdalá A, Casas-Muñoz A, Cerezo-Cantú V, Carballido-Moreno OG, Ordoñez-Franco NA. Maltrato infantil: la neurobiología, estrategia de estudio para el siglo XXI. Acta Pediatr Mex 2020; 41(4): 165-177.

DOI: http://dx.doi.org/10.18233/APM41No4pp165-1771883 


\section{INTRODUCCIÓN}

El maltrato infantil sigue siendo un grave problema de salud pública en México y todo el mundo..$^{1-4}$ Las estrategias para su atención integral han mejorado; sin embargo, los programas para alcanzar la prevención primaria, secundaria y terciaria son deficientes. ${ }^{1,5-7}$

Diversos factores están inmersos en esta cruda situación. De ellos destacan la diversidad socioeconómica y cultural de los pueblos, la existencia de "usos y costumbres", y el predominio de diversos determinantes sociales para la salud, situaciones que enmascaran o restan importancia a los casos de maltrato infantil y sus consecuencias. ${ }^{8-9}$

En el siglo XXI se ha conseguido un avance importante en el estudio del maltrato infantil mediante el enfoque de la neurobiología, al planearse la reingeniería en la investigación de esta "patología". ${ }^{10-11}$ En este campo se plantean tres situaciones que pueden estudiarse y explicarse dentro de este concepto:

1. Desarrollo y explicación de la "replicación transgeneracional" del maltrato infantil. ${ }^{12}$

2. Conocimiento de genes específicos implicados en la "replicación transgeneracional" del maltrato infantil. ${ }^{13-17}$

3. Relación de la "epigenómica" como posible mecanismo de estudio y tratamiento del maltrato infantil. ${ }^{18-19}$

Hoy día persiste la duda de cómo explicar el fenómeno de "replicación transgeneracional" y aunque existen diversas publicaciones, no se ha establecido un resultado convincente. ${ }^{13,20}$

Para conseguir una respuesta satisfactoria es necesario realizar un estudio mucho más profundo del cerebro humano para establecer la función específica de ciertas estructuras relacionadas con el comportamiento violento del hombre, además de su interrelación con los aspectos genéticos y del genoma humano. A lo anterior debe agregarse el análisis de la influencia que el ambiente ejerce en los genes y el genoma mismo del menor agredido en las diferentes épocas de su infancia. ${ }^{21}$

En la actualidad se propone que la interacción temprana entre el cerebro y el ambiente (estímulos negativos o positivos) influye en la salud mental del niño, así como la expresión de ciertas manifestaciones en su vida adulta. ${ }^{22-24}$

Para el abordaje de esta interacción es importante la participación de ciencias que hasta hace algunos decenios no eran consideradas necesarias.

\section{CONCEPTOS BÁSICOS DE AGRESIVIDAD Y VIOLENCIA}

Aunque los hechos y las cifras de actos violentos de cualquier índole, ocurridos en todo el mundo, se mantienen elevados, hasta la fecha no se entiende claramente por qué existe la violencia contra ciertos grupos humanos, así como el comportamiento anormal de los individuos violentos.

Para conocer los orígenes de estas conductas en el hombre es necesario iniciar el estudio desde antes de su nacimiento y, con ello, tratar de establecer la relación con factores como: la herencia, el desarrollo neurológico, psicológico y de ajuste conductual temprano del menor. ${ }^{21,25}$

En condiciones normales, el hombre cuenta con un sistema neurológico denominado "sistema agresividad-control" que le permite afrontar situaciones estresantes, cuya función es modular 
la agresividad e impedir que evolucione hasta la violencia. Este sistema se integra por tres diferentes factores: 1) genéticos, 2) ambientales (individuales, familiares y sociales) y 3 ) culturales.

Desde el punto de vista experimental, se ha demostrado que la agresividad y la violencia tienen una base fisiológica en el sistema nervioso autónomo y una base cognoscitiva en algunos sistemas funcionales complejos del sistema nervioso central, incluidas algunas estructuras de la corteza cerebral. $^{26}$

La mayoría de los sujetos sanos adquiere el autocontrol, la previsión, el juicio situacional y la conciencia social alrededor de los 30 años; sin embargo, el pico de violencia física en el hogar, en la escuela o en la calle ocurre frecuentemente en la adolescencia tardía, cuando aún los aspectos arriba mencionados no han alcanzado su madurez máxima. ${ }^{27}$

En los últimos años se ha establecido que los individuos que sufren depresión, adicciones o intentos suicidas en la adolescencia o la vida adulta temprana, en un alto porcentaje, fueron víctimas de lo que ahora se conoce como "eventos adversos en la infancia". ${ }^{28-30}$

Los sujetos con comportamiento muy agresivo (algunos criminales) y alteraciones psiquiátricas (paranoia, depresión y consumo excesivo de alcohol) son propensos a disfunción de los lóbulos frontales. ${ }^{31-33}$

\section{DEFINICIÓN DE CONDUCTAS VIOLENTAS}

Desde la perspectiva neuropsiquiátrica se han establecido definiciones de la impulsividad, agresividad y conducta violenta, con la finalidad de conciliar los conceptos provenientes de la psicología y neurofisiología. Cuadro 1
Cuadro 1. Perspectiva neuropsiquiátrica de conductas violentas $^{34}$

\begin{tabular}{l|l|}
\hline $\begin{array}{l}\text { Concepto } \\
\text { Impulsividad }\end{array}$ & \multicolumn{1}{c|}{ Definición } \\
& $\begin{array}{l}\text { Respuesta no premeditada del cerebro que } \\
\text { impide controlar los impulsos o deseos. }\end{array}$ \\
\hline Agresividad & $\begin{array}{l}\text { Instinto que lleva al hombre y a otros } \\
\text { animales a combatir con los miembros } \\
\text { de su misma especie. Se agrede a una } \\
\text { persona que es percibida como amenaza. }\end{array}$ \\
\hline $\begin{array}{l}\text { Conducta } \\
\text { violenta }\end{array}$ & $\begin{array}{l}\text { Tendencia social de un grupo de persona } \\
\text { a la agresión. }\end{array}$ \\
\hline
\end{tabular}

En el maltrato infantil participa la agresividad; por tanto, es necesario conocer la respuesta de un individuo ante una situación de estrés y ésta consta de cuatro elementos:

1. Respuesta somática o muscular. En este momento la persona realiza una serie de movimientos musculares que lo ponen en posición de alerta y una expresión facial variable.

2. Participación del sistema nerviosos autónomo. Se caracteriza por una serie de respuestas automáticas para movilizar toda la energía que se requiere ante la situación de emergencia (taquicardia, aumento del flujo sanguíneo a los músculos, sudación).

3. Intervención hormonal. Esta acción viene a reforzar la función autónoma; se libera adrenalina y cortisol para poner al individuo en tensión.

4. Formación de neurotransmisores específicos. La noradrenalina prepara al organismo para responder al estímulo y la serotonina en el control de la agresividad. Cuando la concentración sérica en baja, se incrementa la irritabilidad. 


\section{PARTICIPACIÓN DEL SISTEMA NERVIOSO CENTRAL Y AUTÓNOMO ANTE EL ESTRÉS}

Los eventos interpersonales tempranos, positivos o negativos, repercuten en la organización estructural del cerebro y este efecto modifica la capacidad funcional adaptativa del menor, sobre todo cuando ocurren en los periodos críticos de crecimiento cerebral (del nacimiento a los dos años de edad). Por lo tanto, este crecimiento y desarrollo del sistema nervioso central es susceptible de alterarse por factores medioambientales adversos, como la desnutrición, el abandono, el maltrato, etcétera. ${ }^{21,23}$

En la actualidad se ha demostrado que las personas que sufren ciertas situaciones adversas en los primeros cinco años de vida, padecen depresión, adicciones, pensamiento e intento suicida. Estas situaciones se conocen como "eventos adversos en la infancia". ${ }^{28-30,35-36}$

Establecer cómo los factores antes mencionados son capaces de modelar el sistema nervisos central, incluso antes del nacimiento, y cómo cada persona los percibe y reacciona ante ellos es uno de los problemas por resolver. Para ello es necesario aceptar que el cerebro debe considerarse un órgano biosocial o biomedioambiental y está diseñado para moldearse por la interacción con el ambiente en el transcurso de su vida. ${ }^{21,37}$

Para entender esta concepción es imperativo conocer la anatomía, la neuroinmunoendocrinología cerebral, la plasticidad de los genes y lo cambiante del medio en un comportamiento simultáneo y dinámico.

\section{Neuroanatomía y neurofisiología ante el estrés}

Ante esta situación se encuentran cinco áreas implicadas: tronco-encéfalo; diencéfalo (tála- mo e hipotálamo), sistema autónomo, sistema límbico (hipocampo y la amígdala) y corteza prefrontal. Figura 1

1. Del tronco-encéfalo deben considerarse tres estructuras: el bulbo raquídeo, la protuberancia y el mesencéfalo. En la región central se localiza la formación reticular, que contiene neuronas serotoninérgicas cuya función es hacer llegar este neurotransmisor a una gran parte del cerebro. En la protuberancia se encuentra, además, el "locus coeruleus", que segrega neuronas noradrenérgicas, responsables de liberar adrenalina a diversas partes del cerebro para su estimulación y mantenerlo alerta. En el mesencéfalo se localiza la sustancia gris periacueductal, cuyos circuitos neurales controlan los movimientos de algunas conductas humanas, como el de lucha o quedar inmóvil ante un probable ataque.

2. El diencéfalo alberga al tálamo y al hipotálamo, principalmente. El primero se localiza en su parte dorsal y entre los dos hemisferios cerebrales. Los núcleos ahí localizados procesan la información sensorial y la envían a otras partes del cerebro, como la amígdala y la corteza cerebral. El hipotálamo contiene gran cantidad de núcleos. Ahí se regula la respuesta del sistema autónomo, independientemente de su localización en el cerebro y a través de la hipófisis al sistema endocrino. La acción que ejerce en la hipófisis, ante una situación de estrés, permite la liberación de corticotropina, que estimula las glándulas suprarrenales para producir hormonas esteroideas, como el cortisol. El resultado es un aumento de la glucemia y cambios sutiles en la personalidad (irritabilidad e incremento en la sensibilidad a estímulos externos). ${ }^{13,38}$ 
3. Del sistema autónomo depende gran parte de las respuestas que no están bajo control voluntario (reflejas) al aumentarlas o disminuirlas, según se trate del sistema simpático o parasimpático (sudación, palidez, taquicardia, bradicardia, taquipnea, bradipnea, hipotensión o hipertensión arterial, etc.).

4. En el sistema límbico existen núcleos cerebrales con participación importante en la regulación de la emoción y la memoria; ahí se establece la "huella neuroinmunoendocrina intangible", así considerada al hablar del maltrato infantil. Es la base anatómica de las emociones.

Está constituido por diversas estructuras, entre las que destacan la amígdala y el hipocampo, principalmente. Figura 1

La amígdala es el centro de la conducta agresiva y emocional, como el miedo. De ahí emanan

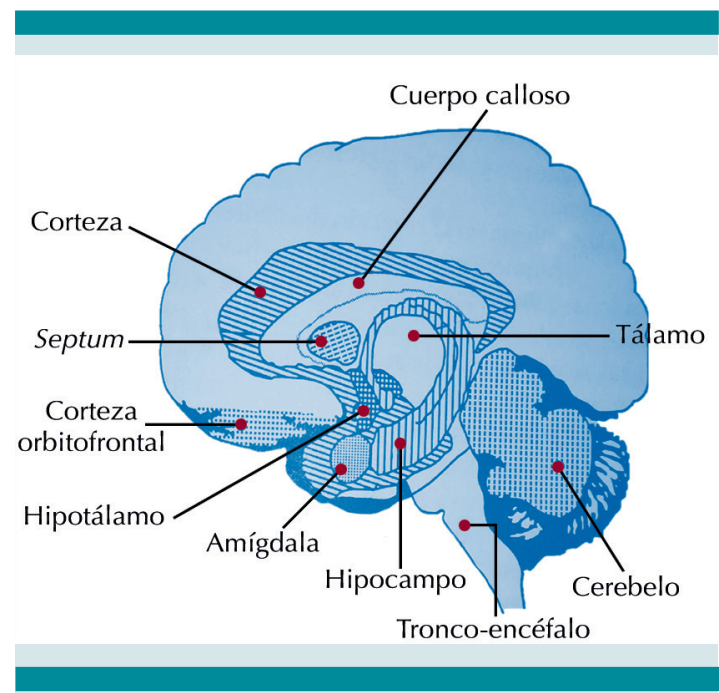

Figura 1. Neuroanatomía básica del cerebro. (Tomado y modificado de: Loredo Abdalá A, Cerezo Cantú V, Corchado Chávez S (2004). las órdenes para que las respuestas somática, autónoma, hormonal y neurotransmisora se efectúen. Su estimulación puede desencadenar reacciones de autodefensa, conductas agresivas, la búsqueda de alimentos o ingestión, incluso la creación del contenido emocional de la memoria (sentimientos relacionados con situaciones de miedo y respuestas agresivas). La señal que el tálamo retransmite a la amígdala permite la aparición de expresiones faciales de miedo u otras; cuando la dirige a la sustancia gris periacueductal se adopta una postura de inmovilidad. Las proyecciones hacia el hipotálamo generan órdenes a los sistemas autónomo y endocrino ya señalados.

En la proyección hacia el troncoencéfalo se estimulan las neuronas noradrenérgicas y serotoninérgicas, generando un estado de alerta e irritabilidad, respectivamente.

El hipocampo es probablemente el centro más importante para la formación y recuperación de la memoria verbal y emocional. Contiene gran cantidad de receptores para el cortisol. La exposición continua y prolongada al cortisol puede alterar significativamente la forma de las neuronas de está región cerebral, debido a su menor tamaño estructural, sobre todo en pacientes con antecedente de abuso sexual o físico..$^{20,27,39}$

5) El lóbulo frontal es otra parte del cerebro con las que se interrelaciona la amígdala. Ahí se efectúan y regulan o controlan funciones consideradas las más "nobles del hombre" (sentimientos, reflexión y conciencia de las emociones).

Con base en la función de la región frontal del hemisferio izquierdo, pueden distinguirse tres zonas características, cuyo comportamiento básico en este fenómeno es el siguiente: 
a) La corteza dorsolateral funciona como un sitio de memoria a corto plazo. Permite elegir entre varias opciones y aprender de los propios errores.

b) La "orbitofrontal" o corteza inferior tiene la capacidad de llevar a la práctica la opción elegida.

c) La ventromedial le da sentido a las percepciones y de esta manera se controlan las emociones.

Definitivamente, la corteza prefrontal controla las emociones y, por ende, las acciones de la amígdala y de las estructuras conectadas con ella.

\section{MODIFICACIONES ESTRUCTURALES Y FUNCIONALES DEL CEREBRO DE UNA VÍCTIMA DE MALTRATO INFANTIL: CONSIDERACIONES NEUROBIOQUÍMICAS}

La intención es encontrar una explicación a la afectación del desarrollo del cerebro generado por el maltrato infantil, principalmente si ha ocurrido tempranamente en la víctima y su replicación transgeneracional. En este sentido, quizá pueda encontrarse un apoyo sustancial, al integrar los conocimientos que se tienen actualmente en la neurobiología del cerebro. ${ }^{40,41}$

Estos conocimientos se apoyan en el entendimiento de algunas consideraciones básicas:

a) Se ha demostrado una alteración del sistema límbico que implica, fundamentalmente, al hipocampo y la amígdala. Esta última podría colocarse en un estado de elevada irritabilidad eléctrica o, bien, el hipocampo quedar dañado como consecuencia de una excesiva exposición al estrés hormonal. b) De manera fehaciente se ha precisado que el tamaño de ambos centros está alterado; en pacientes con antecedente de maltrato infantil es más pequeño el del hemisferio izquierdo que el derecho y habitualmente es normal en individuos que no han sufrido este evento. ${ }^{42}$ Debe considerarse que, característicamente, estas zonas son de las pocas regiones del cerebro que siguen creciendo después del nacimiento.

c) Existe alteración eléctrica de dichos centros; este hecho se sustentado mediante el análisis de los cambios encontrados en estudios electroencefalográficos. ${ }^{43-45}$

d) Existe modificación en la disposición y tamaño de las células receptoras para las hormonas del estrés, fenómeno demostrado en modelos de animales. ${ }^{14-15,46}$

e) Se ha observado marcada alteración en los receptores GABA (inhibidores de la excitabilidad neuronal) localizados en la amígdala.

f) Se ha establecido una disminución en la parte central del cuerpo calloso.

g) La alteración del vermix cerebeloso tiene participación importante en el tratamiento de pacientes con deficiencia de ciertos neurotransmisores, como noradrenalina y dopamina.

Hasta el momento puede concluirse que, puesto que el maltrato infantil ocurre a una edad temprana, es decir, durante la época crítica de modulación física del cerebro, el efecto que ocasiona un estrés importante establece una "huella intangible" en su estructura y función. Esta situación parece desencadenar un fenómeno en cascada de efectos moleculares y neurobioló- 
gicos que alteran irreversiblemente el desarrollo de esta porción cerebral. ${ }^{47}$

El maltrato infantil puede desorganizar o trastornar la maduración normal de las estructuras límbicas, principalmente del hipocampo y la amígdala. Esta última podría colocarse en un estado de elevada irritabilidad eléctrica o, bien, el hipocampo quedar dañado por la excesiva exposición al estrés hormonal.

El estrés es capaz de reconfigurar la organización molecular de estas regiones del cerebro; también se ha observado que los receptores del ácido aminobutírico gama (GABA) establecidos en la amígdala sufren una alteración en su estructura molecular. Estos receptores responden al neuroinhibidor de la transmisión cerebral, atenuando la excitabilidad eléctrica de las neuronas. Cuando disminuye la función de este neurotransmisor, se establece una excesiva actividad eléctrica, que en algunos casos puede estimular las convulsiones.

Las anormalidades electroencefalográficas en víctimas de cualquier forma de maltrato infantil (menores de 18 años y sin diferencia de género) son de 54 vs $27 \%$ de quienes no fueron maltratados. Las anormalidades se localizan en los lóbulos frontal y temporal izquierdos. Las imágenes obtenidas por resonancia magnética se caracterizan por reducción del tamaño del hipocampo izquierdo. ${ }^{43-44}$

\section{TEORÍA DEL VÍNCULO MADRE-HIJO Y SUS VARIACIONES ANTE EL MALTRATO INFANTIL}

Consideración básica en la vida y desarrollo psicoemocional de un niño es el establecimiento del vínculo madre-hijo cuando existe maltrato infantil, porque se modifica durante la infancia del menor maltratado. Al parecer, el apego está estrechamente ligado al sistema límbico derecho, debido a las múltiples conexiones con los sistemas neuroquímicos subcorticales que intervienen en la emoción. ${ }^{48-49}$

\section{INTERVENCIÓN DEL SISTEMA LÍMBICO, CUERPO CALLOSO Y HEMISFERIO DERECHO EN EL MALTRATO INFANTIL}

El hemisferio izquierdo está especializado en la percepción y expresión del lenguaje, mientras que el derecho en el proceso especial de la información, así como en el desarrollo y expresión de las emociones.

Ante estos conocimientos es posible que el niño maltratado almacene las vivencias de los eventos de violencia en el hemisferio derecho y las expresa posteriormente. El desarrollo temprano del hemisferio derecho mantiene conexiones profundas con el sistema límbico y el sistema nervioso autónomo, que es el dominante para la respuesta humana ante el estrés. El predominio del hemisferio derecho en los primeros tres años de vida permite modular y regular la conducta adaptativa-emocional del menor. Por lo tanto, su adecuado funcionamiento favorece el desarrollo óptimo de la resiliencia en etapas posteriores de la vida. Schiffer demostró que ante un reto novedoso existe menor integración de la información emocional en el hemisferio derecho de los adultos que fueron maltratados en alguna época de su niñez. . $3,43-44^{-}$

En este fenómeno también interviene el cuerpo calloso, estructura que establece las conexiones sinápticas interhemisféricas, y que está significativamente disminuido de tamaño en su parte media. Así mismo, entre más temprano ocurre la agresión, la alteración de esta estructura puede ser mayor. El fenómeno parece más significativo en la mujer, sobre todo si se trata de abuso sexual. ${ }^{50}$ 
Por lo tanto, la integración disminuida entre ambos hemisferios y el desarrollo menor del cuerpo calloso pueden predisponer a cambios bruscos en la percepción, estados emocionales y la memoria, por lo que la irritabilidad eléctrica del sistema límbico puede ocasionar síntomas de agresión, exasperación y ansiedad. ${ }^{31,51}$

Ante dicha información debe considerarse que los mecanismos de plasticidad cerebral son capaces de causar una diferenciación del tejido cerebral, con base en la severidad y cronicidad de los estímulos externos; sin embrago, no se ha demostrado su irreversibilidad.

La salud mental adaptativa es la manifestación temprana del niño para crear estrategias conductuales flexibles, que le permiten afrontar las interacciones humanas novedosas y estresantes; estas estrategias tendrán un fuerte respaldo en el vínculo creado con la figura materna, principalmente. Por lo tanto, su adecuado funcionamiento permite el desarrollo óptimo de la resiliencia en etapas posteriores de la vida. ${ }^{23,43-44}$

En resumen, ante las situaciones de estrés, el cerebro reacciona de manera compleja y orquestada, por lo que se han precisado acciones y funciones del eje hipotálamo-hipófisis-suprarrenales, y la liberación de corticotropina (ACTH) y mediadores como: noradrenalina, dopamina, serotonina y GABA para auxiliar y responder la actividad cognoscitiva, emocional, de comportamiento y metabólica que se requiera; sin embargo, no todos los cerebros de los niños agredidos responden de manera similar, por ello existe discrepancia en los diferentes estudios publicados acerca de este tópico. Figura 2

\section{FUNCIÓN DE LA GENÉTICA}

La evidencia circunstancial que reportó el estudio de 1037 niños varones, seguidos desde el

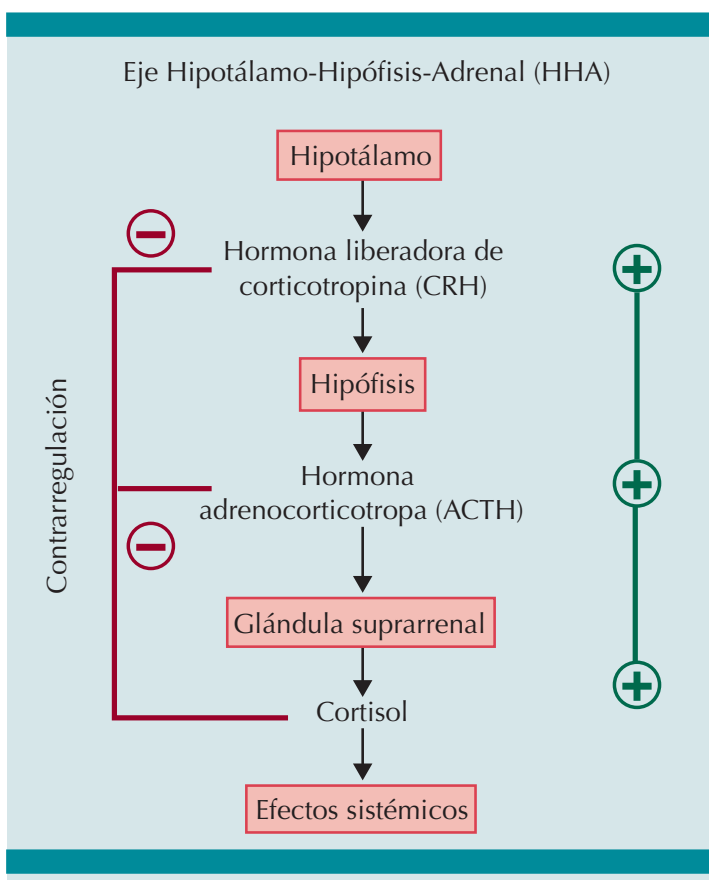

Figura 2. Eje hipotálamo-hipófisis-adrenal. (Creación propia).

nacimiento hasta los 26 años, sugirió la hipótesis de que los niños víctimas de maltrato infantil pueden ser agresores en la vida adulta cuando tienen una mutación en el gen que codifica la producción de monoaminooxidasa A (MAOA); esta deficiencia ocasiona un trastorno en el metabolismo de neurotransmisores como la noradrenalina, serotonina o dopamina. Y cuando la alteración de este sistema neurotransmisor persiste hasta la vida adulta, puede generar una conducta agresiva en el portador de la misma. ${ }^{19,52}$

Otros genes implicados con el maltrato infantil son:

EI NR3C1 (gen que codifica para el receptor de glucocorticoides). ${ }^{53-54}$

El SCL6A4 (gen que codifica para el transportador de serotonina). ${ }^{18,55}$

Como se ha podido demostrar, el maltrato infantil genera cambios en la habilidad del cerebro de la víctima para procesar la información que recibe en 
situaciones de estrés, produciendo cambios fisiológicos y, por lo tanto, conductuales. A su vez, éstos pueden alterar la expresión genética (por medio de la metilación) lo que ocasionará probablemente otros cambios estructurales a este nivel.

Para el estudio de estos genes se ha planteado la necesidad de realizar su búsqueda en animales de experimentación, mediante la toma de tejidos involucrados como: la amígdala, el hipocampo, hipotálamo, corteza prefrontal y sangre periférica. La finalidad es identificar en alguno de ellos, los posibles biomarcadores.

Los avances de la medicina genómica seguramente acelerarán el estudio de los genes que influyen en el comportamiento humano. De confirmarse las mutaciones en algunos genes que influyen en la conducta humana haciéndola agresiva, existirá la oportunidad de identificar a aquellos individuos con alto riesgo de desarrollar dicho comportamiento y con ello será posible implementar algún medicamento, alimento o sustancia para evitar los estímulos ambientales desencadenados.

\section{REPLICACIÓN TRANSGENERACIONAL}

El enfoque de la medicina preventiva para el siglo XXI ha permitido el estudio de la medicina genómica; por lo tanto, diversas enfermedades serán mejor conocidas y entendidas. De esta manera surge la siguiente interrogante: ¿Existe la posibilidad de que la genética, la genómica, o ambas, favorezcan el entendimiento del porqué un niño maltratado pueda tener un comportamiento violento en la edad adulta?

Aunque la evidencia señala que una cantidad significativa de niños maltratados se convierten en agresores de sus propios hijos al Ilegar la vida adulta, aún no se cuenta con una respuesta clara y convincente al respecto. ${ }^{56}$
Para conceptualizar el desarrollo infantil se ha empleado un "modelo transaccional" que considera este fenómeno y su organización cerebral como un proceso de interacción entre: los programas cerebrales, los genes y la influencia del ambiente (epigenética).

La epigenética es la estrategia para encontrar y explicar un mecanismo que permita evitar el desarrollo de la "replicación transgeneracional". 15,57-62

En la actualidad se plantea emplear la epigenética para determinar si existe o no alguna huella bioquímica cerebral que afecte el comportamiento violento en personas que fueron víctimas de maltrato infantil.

Para tal finalidad es probable que el empleo de un modelo animal pueda responder las siguientes interrogantes:

¿Existe diferencia epigenética entre los animales maltratados y los controles?

¿Existe una transmisión de la huella epigenética de los padres que fueron maltratados a la siguiente generación, entiéndase este fenómeno como un predisponente del maltrato infantil?

¿Puede demostrarse si es la madre o el padre quienes transmiten esta huella epigenética?

¿Es posible retar a ciertos tejidos del cerebro o a células germinales de un modelo animal, mediante el empleo de un fármaco, un alimento o alguna substancia de origen natural, para modificar su respuesta?

La caracterización de los mecanismos moleculares de la agresividad probablemente ofrecerá opciones terapéuticas, mediante el empleo de fármacos específicos, alimentos u otras substancias de origen animal. 


\section{EL CEREBRO Y LOS FLAVONOIDES}

El maltrato infantil, en cualquiera de sus modalidades, provoca el desequilibrio de las respuestas físicas y emocionales de la víctima, lo que genera estrés oxidante que al tornarse produce la activación prolongada de los sistemas de estrés corporal. Estas acciones inducen cambios profundos en la citoarquitectura del cerebro, que resulta en una alteración del comportamiento social, el aprendizaje, y la salud física y emocional de la víctima. ${ }^{63}$

El cerebro es un órgano vulnerable a los efectos de las especies reactivas de oxígeno, pues tiene capacidad limitada para desintoxicarse, debido a la baja producción de enzimas antioxidantes, tasa metabólica alta y limitada capacidad de regeneración y reparación. Por lo tanto, el aumento de radicales libres y el déficit de acción defensiva de los antioxidantes favorecen los trastornos neurodegenerativos. Ante estas evidencias es posible obtener una protección neuronal mediante algún medicamento, sustancia o alimento encaminado a la disminución de la producción de estrés oxidante. ${ }^{64}$

La disponibilidad de medicamentos para este tipo de trastornos no es viable hoy día. Sin embargo, es posible recurrir a los flavonoides, compuestos que se encuentran en ciertos alimentos (vegetales, frutas rojas y cítricas, chocolate, semillas) o bebidas (vino tinto, té verde, té negro, cerveza), que cuentan con propiedades antiinflamatorias, antineoplásicas, antibacterianas, entre otras. A pesar de sus beneficios, debe considerarse que el consumo excesivo de flavonoides puede propiciar la sobreproducción de especies reactivas de oxigeno y provocar las complicaciones arriba descritas. ${ }^{65}$

Entre los alimentos con alto contenido de flavonoides se encuentra el cacao (chocolate), pues contiene epicatequina y catequina, productos con potente actividad antioxidante y capacidad de vasodilatación, acciones que pueden evitar el daño oxidante en el cerebro. ${ }^{66-67}$

Este conocimiento da la pauta para desarrollar diversos protocolos de investigación, empleando modelos de animales para retar a ciertos tejidos del cerebro o a células germinales, mediante el empleo de algún fármaco, alimento o sustancia de origen natural, con la intención de modificar su respuesta.

Si se obtienen resultados positivos, el uso de chocolate con flavonoides podría implementarse como una nueva alternativa terapéutica y preventiva, considerando su efecto beneficioso en la función cognitiva. ${ }^{68}$

\section{CONCLUSIONES}

El tratamiento multidisciplinario del maltrato infantil, establecido a nivel mundial en los últimos decenios, ha enriquecido su entendimiento. La neurobiología, la teoría del vínculo maternoinfantil (desde la perspectiva psicológica) y la medicina genómica han aportado nuevas explicaciones, apoyadas en el uso de tecnologías que permiten explicaciones actuales a las interrogantes planteadas al inicio de este trabajo.

Si las condiciones mínimas requeridas para que un niño logre el desarrollo óptimo de su personalidad están ausentes o han sufrido carencias notables, es posible que las funciones aprendidas tempranamente en comunicación, afecto y socialización repercutan en la vida adulta. Sin embargo, debe considerarse que esta situación ocurre en todos los niños, pues su capacidad de aprendizaje y resiliencia, como mecanismo de defensa en etapas posteriores de la vida, los protege ante la experiencia de abuso o maltrato. 
En el proceso de aprendizaje participan ciertas habilidades sociales (comunicación, relación interpersonal, afrontamiento ante el estrés, etc.) que se adquieren durante la vida. En este fenómeno participan diferentes estructuras, como el sistema nervioso central, autónomo, endocrino y áreas médicas (genética y genómica), no sólo como un paradigma teórico, sino como una realidad creciente a la que no se le ha dado el valor social necesario. Por lo tanto, para que exista una cultura de prevención ante el maltrato infantil en sus diferentes modalidades, debe comprenderse esta interrelación, porque el efecto del maltrato no sólo implica al presente, sino que ciertas consecuencias se observan a futuro, cuando se ponen a prueba los roles aprendidos en la infancia, principalmente el paterno-materno.

Es importante que los profesionales que atienden este problema médico-social-legal de la humanidad, se mantengan en constante comunicación entre sí para desarrollar un mejor frente en la atención integral, sobre todo en la prevención de la violencia intencional o no accidental contra los niños y adolescentes del mundo. También es decisivo buscar nuevas estrategias preventivas del fenómeno, incluida la participación de biólogos, genetistas e investigadores básicos, en conjunto con investigadores clínicos para evitar este flagelo de la humanidad en nuestra sociedades.

\section{REFERENCIAS}

1. UNICEF. Panorama Estadístico de la Violencia contra Niñas, Niños y Adolescentes. 1a ed. Ciudad de México, México. 2019

2. Instituto Nacional de Salud Pública y UNICEF México. Encuesta Nacional de Niños, Niñas y Mujeres 2015.

3. Organización Mundial de la Salud (2016). Maltrato Infantil. https://www.who.int/es/news-room/fact-sheets/detail/ child-maltreatment el día 15/07/2019
4. Loredo-Abdalá A. Maltrato infantil: consideraciones básicas para el diagnóstico de la formas más preponderantes. Act Pediatr Mex 2008;29:255-61.

5. Organización Mundial de la Salud. Prevención del maltrato infantil: Qué hacer, y cómo obtener evidencias. 2006

6. Loredo-Abdalá A. Maltrato infantil: ¿̇conocer su impacto económico favorece su prevención? Act Pediatr Mex 2016;37:1-3.

7. Loredo-Abdalá A. El maltrato infantil: conceptos básicos para cambiar de utopía a realidad en México. Act Pediatr Mex 2008;29:253-254.

8. Organización Mundial de la Salud. Subsanar las desigualdades en una generación. Alcanzar la equidad sanitaria actuando sobre los determinantes sociales de la salud. Buenos Aires: Ediciones Journal, 2009.

9. Loredo-Abdalá A, et al. El maltrato infantil: Conceptos básicos de una patología médico social legal. Revista de la Facultad de Medicina UNAM 2013; 56: 5-10.

10. Loredo-Abdalá $\mathrm{A}$, et al. Neurobiología del niño maltratado: enfoque básico para el siglo XXI. En: Loredo Abdalá A. Maltrato en niños y adolescentes (pp. 262-275). Ciudad de México: Editores de Textos Mexicanos, 2004.

11. Salinas $S$, et al. Epigénesis: secuelas de una infancia adversa. Rev Dig Univers 2019;20:1-13. http://doi.org/10.22201/ codeic.16076079e.2019.v20n2.a1

12. Finkelhor D, et al. Children's Exposure to Violence: $A$ Comprehensive National Survey". Juvenile Justice Bulletin. Departamento de Justicia de los Estados Unidos, Oficina de Justicia Juvenil y Prevención de la Delincuencia, octubre de 2009. https://www.ncjrs.gov/pdffiles1/ ojjdp/227744.pdf

13. Provençal $\mathrm{N}$, et al. The effects of early life stress on the epigenome: From the womb to adulthood and even before. Experim Neurol 2015;268:10-20. DOI: 10.1016/j. expneurol.2014.09.001

14. Weaver I, et al. Epigenetic programming by maternal behavior. Nat Neurosci. 2004;7:847-854. DOI: 10.1038/nn1276

15. Franklin T, et al. Epigenetic Transmission of the Impacto of Early Stress Across Generations. Biol Psychiatry 2010;68:408-415. DOI:

16. Yehuda R, et al. Holocaust Exposure Induced Intergenerational Effects on FKBP 5 Methyltion 2016;80:372-380. DOI: 10.1016/j.biopsych.2015.08.005

17. Rodgers A, et al. Paternal stress exposure alters sperm microRNA content and reprograms ofspring HPA stress axis regulation. J Neurosci 2013;22:9003-9012. DOI: 10.1523/ JNEUROSCI.0914-13.2013

18. Wang D, et al. Peripheral SLC6A4 methylation is associated ith in vivo measures of human brain serotonin synthesis and childhood physical aggression. PloS One 2012;7:e39501. DOI: 10.1371/journal.pone.0039501

19. Caspi $A$, et al. Role of genotype in the cycle of violence in maltreated children. Science 2002;297:851-853. DOI: 10.1126/science.1072290 
20. Mesa P, et al. Neurobiología del maltrato infantil: el 'ciclo de la violencia'. Rev Neurol 2011;52:489-503. DOI: https:// doi.org/10.33588/rn.5208.2009256

21. Lupien S, et al. Effects of stress throughout the lifespan on the brain, behaviour and cognition. Nat Neurosci 2009;10:434-445. DOI: 10.1038/nrn2639

22. Grady $M$, et al. Linking adverse childhood effects and attachment: a theory of etiology for sexual offending. Trauma Violence Abus 2017;18:433-444. DOI: $10.1177 / 1524838015627147$

23. Schore N. The Effects of secure attachment reltionship on right brain development, affect regulation, and infant mental health. Infant Mental Health Journal 2001;22:7-66. https://doi.org/10.1002/10970355(200101/04)22:1<7::AID-IMHJ2>3.0.CO;2-N

24. Lapp $\mathrm{H}$, et al. Early life exposure, neurodevelopmental disroders, and transposable elements. Neurobiol Stress 2019;11:1-14. https://doi.org/10.1016/j.ynstr.2019.100174

25. Jaffee $S$, et al. Nature x nurture: Genetic vulnerbilities interact with physical maltreatment to promote conduct problems. Dev Psychopathol 2005;17:67-84. https://www. ncbi.nlm.nih.gov/pmc/articles/PMC2768347/

26. Craig I, et al. Genetics of human aggresive behaviour. Hum Gent 2009;126:101-113. DOI: 10.1007/s00439-009-0695-9

27. Rosell DR, et al. The neurobiology of aggression and violence. CNS Spectrums 2015;20(3):254-79. doi:10.1017/ S109285291500019X

28. Felitti VJ, et al. Relationship of childhood abuse and household dysfunction to many of the leading causes of death in adults. The Adverse Childhood Experiences (ACE) Study. Am J Prev Med 1998;14:245-258. DOI:https://doi.org/10.1016/ S0749-3797(98)00017-8

29. Anda R, et al. Adverse childhood experiences, alcoholic parents, and later risk of alcoholism and depression. Psychiatric Serv 2002;53:1001-1009. DOI: 10.1176/appi. ps.53.8.1001

30. Choi N, et al. Adverse childhood experiences and suicide attempts among those with mental and substance use disorders. Child Abuse Neglect 2017;69:252-262. DOI: 10.1016/j.chiabu.2017.04.024

31. Blake $P$, et al. Neurologic abnormaliies in murderes. Neurology 1995;45:1641-1647. DOI: 10.1212/wnl.45.9.1641

32. Bechara $A$, et al. Decision-making deficits, linked to a dysfuntional ventromedial prefrontal cortex, revealed in alcohol and stimulant abusers. Neuropsychologia 2001;39:376-389. DOI: 10.1016/s0028-3932(00)00136-6

33. Marazziti D, et al. The neurobiology of moral sense: facts or hypotheses? Annals General Psychuatry 2013;12:6. http:// www.annals-general-psychiatry.com/content/12/1/6

34. Téllez E. Neurobiología de la conducta agresiva. En: Gavrina M y Téllez (eds). Neuropsiuíatria: imágenes del cerebro y la conducta. Bogotá: Fundación Cultural Javeriana, 1995.
35. Lynn M, et al. The Effect of Adverse Childhood Experience on Clinical Diagnosis of a Substance Use Disorder: Results of a Nationally Representative Study. Subst Use Misuse 2017;50:689-697. DOI: 10.1080/10826084.2016.1253746

36. Duffy K, et al. Early life adversity and healt-risk behaviors: proposed psychological and neural mechanisms. Ann NY Acad Sci 2018;40:1-19. DOI: 10.1111/nyas.13928

37. Gibson KR. The biocultural human brain, seasonal migrations, and the emergence upper paleolithic. En: Mellars $P$, and Gibson KR (eds). Modeling the human mind. Cambridge, England: McDonald Institute for Archeological Research, 1996: 33-36.

38. Cichetti $D$, et al. Diverse patterns of neuroendocrine activity in maltreated children. Dev Psychopathol 2001;13:677-693. DOI: $10.1017 / \mathrm{s} 0954579401003145$

39. Teicher M, et al. The neurobiological consequences of early stress and childhood maltreatment. Neurosci Biobehav Rev 2003;27:33-44. DOI: 10.1016/s0149-7634(03)00007-1

40. Kaufman J, et al. Effects of early adverse experiences on brain structure and function: clinical implications. Biol Psychiatry 2000;48:778-790. DOI: 10.1016/s00063223(00)00998-7

41. Bönke L, et al. Examining the effect of Early Life Stress on autonomic and endocrine indicators of individual stress reactivity. Neurobiology Stress 2018;10:100142. DOI: 10.1016/j.ynstr.2018.100142

42. Cassiers LLM, et al. Structural and functional brain abnormalities associated with exposure to different childhood trauma subtypes: a systematic review of neuroimaging findings. Front Psychiatry 2018;9:329. DOI: 10.3389/ fpsyt.2018.00329

43. Teicher M. Scars that won't heal: The neurobiology of child abuse. Sci Am 2002;286:54-61. DOI: 10.1038/scientificamerican0302-68

44. Teicher M, et al. Developmental neurobiology of childhood stress and trauma. Psychiat Clin Am 2002;25:397-426. DOI: 10.1016/s0193-953x(01)00003-x

45. Collado MA, et al. Alteraciones del sueño en niños víctimas de abuso físico o sexual. Cir Ciruj. 2005; 73: 297-301

46. Caldij $C$, et al. Maternal care during infancy regulates the development of neural systems mediating the expresión of fearfulness in the rat. Proc Nat Acad Sci USA 1998;95:53355340. DOI: 10.1073/pnas.95.9.5335

47. DeBellis MD, et al. Developmental traumatology. Part II. Brain development. Biol Psychiatry 1999; 45: 1271-1284. DOI:https://doi.org/10.1016/S00063223(99)00045-1

48. Bowlby J. Vínculo afectivos: formación, desarrollo y pérdida. Madrid: Morata, 1999.

49. Benoit D. Infant-prent attachment: Definition, types, antecedents, measurement and outcome. Paediatr Child Health 2004;9:541-545. DOI: 10.1093/pch/9.8.541 
Loredo-Abdalá A, et al. Neurobiología del maltrato infantil

50. Andersen S, et al. Preliminary evidence for sensitive periods in the effect of childhood sexual abuse on regional brain development. J Neuropsychiatry Clin Neurosci 2008;20:292301. DOI: 10.1176/jnp.2008.20.3.292

51. Teicher $\mathrm{M}$, et al. Childhood neglect is associated with reduced corpus callosum area. Biol Psychiatry 2004;56:80-85. DOI: 10.1016/j.biopsych.2004.03.016

52. Shih JC, et al. Monoamine oxidase: from genes to behavior. Annu Rev Neurosci 1999;22:197-217. DOI: 10.1146/ annurev.neuro.22.1.197

53. Nelson E. Abuse cast a long shadow by changiny children's genes. Epigenetic changes from abuse put victims at risk not just for chronic psychological problems, but physical ones, too. Nova 2014

54. McGowan $P$, et al. Epigenetic regulation of the glucocorticoid receptor in human brain associates with childhood abuse. Nat Neurosci 2009;12:342-348. https://www.ncbi. nlm.nih.gov/pmc/articles/PMC2944040/

55. Raad R, et al. Impact of behavioral genetic evidence on the perceptions and dispositions of child abuse victims. Public Health Genomics 2015;18:11-19- https://www.ncbi.nlm. nih.gov/pmc/articles/PMC4289447/

56. Loredo-Abdalá A. Maltrato Infantil: Gravedad y Prevención. Ciudad de México: Editores de Textos Mexicanos, 2017.

57. OECD. Social spending across. Capí the Child's life cycle. En: OECD, Doing better for children. Capítulo 2; OECD. Comparative Child Well-being across. OECD Publishing; 2009. https://www.oecd.org/social/family/43570328.pdf

58. Thornberry TP, et al. Intergenerational continuity in maltreatment. Journal Abnormal Childhood Psychology 2013;41:555-569. https://www.ncbi.nlm.nih.gov/pmc/ articles/PMC3640695/

59. Karatekin C, et al. Effects of Adverse Childhood Experiences, Stress, and Social Support on the Health of College Students. J Interper Violence 2016:1-23. DOI: $10.1177 / 0886260516681880$
60. Kerker BD, et al. Do Pediatricians Ask About Adverse Childhood Experiences in Pediatric Primary Care?. Acad Pediatr 2016;16:154-160. https://www.ncbi.nlm.nih.gov/ pmc/articles/PMC4779699/

61. Hughes $\mathrm{K}$, et al. The effect of multiple adverse childhood experiences on health: a systematic review and meta-analysis. Lancet Public Health 2017;2:e356-66. DOI:https://doi.org/10.1016/S2468-2667(17)30118-4

62. Dixon $L$, et al. Risk factors of parents abused as children: a meditational analysis of the international continuity of child maltreatment (Part 1). J Child Psychol Psych 2005;46:47-57. DOI: 10.1111/j.1469-7610.2004.00339.x

63. Jackson A, et al. Aspects of abuse: consequences of childhood victimization. Curr Probl Pediatr Adolesc Health Care 2015;45:86-93. DOI: 10.1016/j.cppeds.2015.02.004

64. Hyder Samina, Abdullah Abir. Neuroprotective effect of quercetin in murine cortical brain tissue cultures. Clin Nutr Exper 2019;23:89-96. https://doi.org/10.1016/j. yclnex.2018.10.002

65. Estrada R, et al. Los flavonoides y el Sistema Nervioso Central. Salud Mental 2012;35:375-384. https://www. redalyc.org/pdf/582/58225155004.pdf

66. Sokolov A, et al. Chocolate and the brain: Neurobiological impact of cocoa flavanols on cognition and behavior. Neurosci Biobehav Rev 2013;37:2445-2453. DOI: 10.1016/j. neubiorev.2013.06.013

67. Santamaria $D$, et al. Comparative effects of catechin, epicatechin and $\mathrm{N}-\Omega$-nitroarginine on quinolinic acidinduced oxidative stress in rat striatum slices. Biomed Pharmacother 2016;78:210-215. DOI: 10.1016/j. biopha.2016.01.016

68. Crichton $\mathrm{G}$, et al. Chocolate intake is associated with better cognitive function: The Maine-Syracuse Longitudinal Study. Appetite 2016;100:126-132. DOI: 10.1016/j. appet.2016.02.010 